\title{
Thyroid hemiagenesis
}

INSERM

\section{Source}

INSERM. (1999). Orphanet: an online rare disease and orphan drug data base. Thyroid hemiagenesis. ORPHA:95719

Thyroid hemiagenesis is a form of thyroid dysgenesis (see this term) characterized by an absence of half of the thyroid gland that is usually asymptomatic but may result in primary congenital hypothyroidism (see this term), a permanent thyroid deficiency that is present from birth. 